\title{
Desenvolvimento cognitivo e afetivo dos estudantes de Contabilidade - influência do método de caso à luz da Taxonomia de Bloom
}

\author{
Michele Urrutia Heinz \\ 0000-0002-9410-3734 | E-mail:michelleurrutia@bol.com.br
}

Alexandre Costa Quintana

0000-0001-6896-9465 | E-mail: professorquintana@hotmail.com

Ana Paula Capuano da Cruz

0000-0002-6064-1614 | E-mail: anapaulacapuanocruz@hotmail.com

\section{Resumo}

Objetivo: avaliar o desenvolvimento cognitivo e afetivo alcançado com a técnica de ensino de método de caso, com base na Taxonomia de Bloom em estudantes do curso de Ciências Contábeis de uma Instituição Federal de Ensino Superior (Ifes).

Método: Quase-experimento em grupo de alunos (intacto sem seleção), na disciplina Estrutura das Demonstrações Contábeis do $4^{\text {a }}$ semestre, durante o primeiro semestre de 2018.

Resultados: Revelam que a utilização de uma técnica de ensino ativa, como um instrumento complementar, possui a capacidade de influenciar o nível de desenvolvimento cognitivo e afetivo alcançado pelos estudantes, estimulando também, a tomada de decisão, comunicação e a resolução de problemas, além de propiciar um ambiente de aprendizagem mais interativo, dinâmico, reflexivo e motivador, tornando os estudantes responsáveis pela própria aprendizagem, proporcionando, assim, ação e interação do sujeito com o seu objeto de estudo, elementos essenciais e pertinentes para a construção de conhecimento.

Contribuições: Os dados levantados nesta pesquisa permitem inferir que o uso do método de caso, como técnica complementar de ensino, contribuiu com o desenvolvimento da aprendizagem superficial, pois ampliou o nível de desenvolvimento mais básico, além de ter auxiliado na ampliação de todos os níveis cognitivos de forma parcial e proporcionado a motivação nos estudantes.

Palavras chave: Método de caso. Desenvolvimento cognitivo e afetivo. Taxonomia de Bloom. 


\section{Introdução}

A busca constante pela qualidade da educação impõe desafios diários aos docentes. Nesse contexto, a necessidade de adaptação é motivada por inúmeras questões, tais como programas impostos pelo Governo como ocorreu com a implantação da Reestruturação e Expansão das Universidades Federais (Reuni), que ampliou o número de vagas na educação superior (Pavione, Avelino \& De Souza Francisco, 2016), ou ainda, em função de mudanças propostas na legislação contábil, como aquelas ocorridas com as alterações da Lei no 6.404/1964, definidas a partir das Leis n. ${ }^{o s} 11.638 / 2007$ e 11.941/2009. Esses fatores demandaram dos docentes uma adaptação; o primeiro quanto à ampliação na quantidade de alunos em sala de aula; e o segundo, quanto à necessidade imediata de atualização sobre as novas exigências contábeis.

A qualidade do ensino está associada ao relacionamento estabelecido entre o docente, o discente e a estrutura institucional. Portanto, é imprescindível compreender como esses interagem para um melhor desenvolvimento do processo educacional (Souza Gil, Garcia, Lino \& Gil, 2012). Neste sentido, reavaliar as estratégias utilizadas, buscando construir um ambiente motivador para a formação de nível superior, também é considerado um desafio para o docente (Souza Gil et al. 2012).

Almejando ampliar a qualidade da educação e o comprometimento dos estudantes, os docentes recorrem à utilização de estratégias de ensino que envolva ativamente estes estudantes no processo acadêmico (Guimarães, Severo, Nobrega, \& Leone, 2019). Além de proporcionar a reflexão dos docentes sobre as metodologias empregadas, o uso de diferentes estratégias de ensino podem melhorar os níveis de compreensão sobre os conteúdos abordados (Carneiro, Portes \& Cavalcante, 2014). Neste sentido, a metodologia utilizada é fator determinante para facilitar a aprendizagem, visto que os discentes têm disposição e são dedicados quando são motivados por uma técnica de ensino adequada, ou seja, aquela que desperte "a atenção e o interesse dos alunos pela disciplina", estimulando o processo de aprendizagem (Morozini, Cambruzzi \& Longo, 2007, p.97).

Outro ponto considerado importante e de grande relevância, no contexto da aprendizagem, é a análise dos estilos de aprendizagem de cada indivíduo, pois por meio dela é possível verificar capacidades de o estudante processar as informações (Butzke \& Alberton, 2017). Essas capacidades, segundo os autores, são diversas e, portanto, esta percepção proporciona ao docente definir, de maneira apropriada, o método que utilizará. Portanto, torna-se proeminente reconhecer que, por existir a diversidade de estilos de aprendizagem, é essencial a utilização de diferentes técnicas de ensino, visto que as diferentes características do indivíduo justificam o uso de diferentes técnicas de ensinamento (Leal, Miranda \& Casa Nova, 2017).

Dentre as técnicas de ensino disponíveis na literatura, destaca-se o método de caso. Trata-se de um estudo clínico de uma situação, utilizado para estimular o pensamento crítico, desenvolver habilidades de resolver problemas e concentrar a aprendizagem de uma área (Rios, 2011). É uma técnica que permite ao docente envolver a participação do estudante no processo de ensino, proporcionando que os discentes reflitam sobre um problema apresentado, desenvolvendo argumentos, avaliando a situação e propondo soluções (Leal, Medeiros \& Ferreira, 2017).

Segundo Rama (1998), as técnicas que utilizam a resolução de problemas reais, podem oportunizar ao estudante uma experiência de aprendizagem mais rica do que as utilizadas nos modelos tradicionais. Esta estratégia tem como objetivo proporcionar ao estudante uma aproximação com uma situação real profissional; estimular a capacidade de análise diagnóstica; aprender a aplicar informações a situações reais; desenvolver a capacidade de trabalho em equipe; analisar problemas e propor soluções (Leal, Medeiros \& Ferreira, 2017). Neste sentido, além de estimular o estudante a partir de técnicas complementares, também é necessário acompanhar o efeito do uso dessa técnica em seu desenvimento cognitivo e afetivo, uma vez que esses processos ocorrem no sujeito por meio de sua interação e experiência com o objeto de estudo (Pillete, \& Rossato, 2018). 
Diante desse cenário, considera-se que o uso complementar de técnicas de ensino ativas pode representar uma estratégia promissora para a manutenção do campo da Contabilidade no cenário acadêmico, além de auxiliar na preparação da didática do docente haja vista os desafios impostos pelo Reuni, pelas alterações recentes na legislação contábil e também pelas expectativas de uma nova geração de alunos. Neste sentido, este estudo buscou responder ao seguinte questionamento: De que forma o uso do método de caso, como instrumento complementar ao método tradicional, influencia no nível de desenvolvimento cognitivo e afetivo alcançado pelos estudantes de contabilidade?

Buscando-se responder a esse questionamento, avaliou-se a capacidade da técnica de método de caso influenciar nos níveis de desenvolvimento cognitivo (aprendizagem) e afetivo (motivação) atingido pelos estudantes de Contabilidade, à luz da Taxonomia de Bloom. Dessa forma, a investigação contribui com a prática educacional, indicando que é benéfica, para o ensino da Contabilidade, a utilização da técnica de método de caso como complemento à aula expositiva e à resolução de exercício, visto que proporciona um desenvolvimento cognitivo mais elevado e profundo nos estudantes, permitindo aos docentes utilizar esses dados como um instrumento de análise, diante dos objetivos educacionais que pretendem alcançar, e se sintam estimulados com as possibilidades, assim como os resultados encontrados demonstraram que o uso dessa metodologia ativa contribui com o processo de ensino e aprendizagem, possibilitando aos docentes refletir sobre sua prática.

Como contribuição teórica, destaca-se o resgate realizado acerca da formação da construção do conhecimento, evidenciando o Construtivismo como um formato que permite o desenvolvimento cognitivo do estudante e, consequentemente, a construção de conhecimento, demonstrando seu efeito por meio das avaliações realizadas. O estudo colaborou, também, com os estudantes, que, pela da aplicação da técnica experimental, obtiveram um ambiente de aprendizagem com integração, trabalho em grupo, desenvolvimento da experiência de resolver problemas e tomar decisões, aperfeiçoando a comunicação, a realização de pesquisa e, principalmente, proporcionado um ambiente capaz de melhorar o desenvolvimento cognitivo, trazendo satisfação. A satisfação pode ser um indicador de qualidade. Nesse sentido, sua análise foi fundamental para compreender os processos que precisam ser melhorados, servindo de base para a gestão das Ifes rever os planos e propostas educacionais.

\section{Referencial teórico}

Baseando-se na teoria Cognitivista, quando se trata do estudo da aprendizagem, a preocupação centra-se em como o sujeito interage com o objeto de estudo por meio de sua estrutura mental (Moreira, 2011). Assim, o cognitivismo fundamenta-se nas suposições de que a aprendizagem atual depende da anterior, analisando como o sujeito processa as informações e atribui significado a elas (Lefrançois, 2016). Nesse sentido, o desenvolvimento é visto como resultado da interação dos processos de pensamento do sujeito com as ações externas (Piletti \& Rossato, 2011). Assim, o conhecimento é compreendido a partir da cognição humana, como um processo de construção (Moreira, 2011).

O conhecimento é desenvolvido, por meio de mecanismos mentais utilizados pelo sujeito para traduzir o mundo, e por isso não pode ser transferido, pois é consequência da informação incorporada e assimilada pelo sujeito durante todas as etapas de sua vida (Piaget, 1970). Dentro desse contexto, torna-se relevante discorrer sobre a formação do conhecimento no sujeito, abordando questões, como o desenvolvimento cognitivo e afetivo dos estudantes; e apresentar uma forma de avaliação da aprendizagem decorrente da experiência dos sujeitos. 


\subsection{Formação do Conhecimento}

O conhecimento é o resultado do confronto entre sujeito e objeto; assim "a função do sujeito é aprender sobre o objeto e a do objeto é ser apreensível e ser aprendido pelo sujeito" (Hessen, 2003, p. 20). Assim, analisando o conhecimento a partir do sujeito, o objeto pertence de forma transcendente a ele, pois é o sujeito que sofre alterações na sua função cognitiva, da qual emite uma imagem representativa das determinações do objeto (Hessen, 2003).

O conhecimento resulta da ação e interpretação. Assim, para conhecer um objeto, é necessário que o sujeito transforme esse objeto em conhecimento e capte seus mecanismos, para que possa assimilá-lo ou acomodá-lo, sendo construído por este sujeito (Piaget, 1970). Este conhecimento não é algo acabado, é constituído pelo sujeito por meio de sua interação com o meio físico e social. Desse modo, a aprendizagem só possui sentido se acontece por intermédio do movimento das estruturas da consciência (Becker, 1992). Assim, para o autor, a "educação deve ser um processo de construção do conhecimento" e, não, uma ideologia de transmissão (Becker, 1992, p. 10).

Nesse sentido, o conhecimento, a partir de uma linha construtivista, não é unicamente decorrente da inteligência (das estruturas cognitiva, afetiva e psicomotora), mas também das experiências vivenciadas pelo sujeito ao longo de sua vida. Logo, o conhecimento é construído pelo processo espontâneo (Piaget, 1970). Assim, a teoria do Desenvolvimento Cognitivo, criada por Piaget, é fundamental para compreender a aprendizagem (Moreira, 2011), visto que é fruto do que acontece no organismo do sujeito, como consequência da sua experiência (Lefrançois, 2016). Esta experiência também é considerada pela andragogia, que defende o princípio de que o professor deve considerar as experiências vivenciadas pelo aluno, pois são elas que relacionam o conhecimento com a as situações reais, dando sentido aos objetos de estudo (Knowles, Holton \& Swanson, 2012).

A aprendizagem é considerada ativa quando é realizada por meio de qualquer técnica que envolva o aluno, exigindo que este realize atividades significativas e reflita sobre o que está fazendo (Prince, 2004). Assim, considera-se que aprender é um processo integrado, composto pelo intelecto, pela afetividade e pelo sistema muscular, que proporciona ao sujeito da aprendizagem adquirir novos conhecimentos (Bordane, \& Pereira, 2015). Sob a égide dessa visão, é necessário que a forma de avaliação da aprendizagem possibilite ao docente verificar o quanto o seu trabalho está sendo eficiente e ao aluno o nível de desenvolvimento cognitivo que se encontra (Luckesi, 2014).

\subsection{Avaliação da aprendizagem}

A avaliação da aprendizagem possibilita realizar diagnósticos do desenvolvimento do conhecimento e das dificuldades ocorridas, permitindo ao docente analisar o progresso do ensino, propondo ajustes em busca da qualidade do ensino (Lopes \& Carvalho, 2017). O princípio geral da avaliação é verificar se os objetivos traçados e propostos foram atingidos, estando relacionada à avaliação do próprio trabalho do docente. Assim, ao avaliar os avanços e dificuldades dos estudantes, o docente realiza um diagnóstico de sua prática pedagógica (Haydt, 2011). Para a autora, esse mecanismo possibilita-lhe reavaliar e propor aperfeiçoamentos e, por este motivo, a avaliação é considerada como um instrumento que contribui para a melhoria da qualidade da aprendizagem e do ensino.

Analisando a avaliação pela ótica da psicologia Genética, de Piaget, compreende-se que a educação se desenvolve através das vivências e experiências dos estudantes, que é visto como um ser ativo e participativo na construção do seu conhecimento (Haydt, 2011). Nesse sentido, a unidade educacional é vista como um local privilegiado que desenvolve a construção de conhecimentos e valores. Seguindo essa linha, a avaliação deve ser visualizada como um processo constante que permite interpretar conhecimentos, habilidades e atitudes desenvolvidas pelos alunos (Barbosa, 2008). 
Com base no exposto, é adequado utilizar modelos de avaliação, baseando-se em competências, cujo foco é o aluno. Nesse sentido, destaca-se a Taxonomia de Bloom - uma ferramenta metodológica que permite estabelecer os objetivos educacionais (Oliveira, Pontes \& Marques, 2016). Essa taxonomia evidencia "em uma hierarquia da aprendizagem partindo de habilidades cognitivas mais simples, como o conhecimento memorizado, até as mais complexas, como o ato de analisar ou avaliar" (Oliveira, Pontes \& Marques, 2016, p. 13).

\subsection{Taxonomia de Bloom}

A Taxonomia de Bloom é um instrumento criado para classificar o que se espera que o estudante aprenda, como resultado de uma instrução, possibilitando medir o objetivo educacional: a aprendizagem (Krathwohl, 2002). Este instrumento funciona como um plano de classificação dos resultados educacionais por meio da investigação das mudanças produzidas nos estudantes, como resultados de suas experiências educativas (Bloom Engelhart, Furst, Hill, \& Krathwohl, 1977) (Bloom et al., 1977). De acordo com os autores, a taxonomia apresenta como limites os objetivos: conhecimento, habilidades intelectuais e capacidade técnica intelectual, denominados "domínio cognitivo". Além disso, contempla a afetividade, que está relacionada ao interesse individual (Bloom, Hastings \& Madaus, 1971).

O desenvolvimento dos elementos referente ao domínio cognitivo reúne os objetivos educacionais em seis categorias: (1) conhecimento: capacidade de recordar ou reconhecer fatos, métodos e processos na forma semelhante a que foi aprendida, (2) compreensão: representa uma captação ou interpretação, a partir de conhecimentos anteriores, (3) aplicação: refere-se ao uso de abstrações em situações específicas ou concretas, recordadas da memória e aplicadas a uma circunstância., (4) análise: expressa a relação entre as ideias, comparando a informação, (5) síntese: reúne elementos e partes para formar um todo, constituindo um esquema que não estava claro ou presente, e (6) avaliação: formula juízo, concepções para determinados propósitos, a partir de critérios determinados ou sugeridos (Bloom et al., 1977), A taxonomia sofreu uma revisão 45 anos após sua elaboração, passando a ser analisada por duas dimensões: o conhecimento e os processos cognitivos, ou seja, o conhecimento passa a ser relacionado com todos os elementos categorizados (Krathwohl \& Anderson, 2010).

Nessa nova construção, os graus apresentados por Krathwohl (2002) se referem a: (1) lembrar, caracterizando o processo de recuperar conhecimentos relevantes contidos na memória de longo prazo; (2) entender, elaborando significado para as mensagens de instrução, por meio da interpretação, exemplificação, classificação, resumo, inferência, comparação e explicação; (3) aplicar, realizando ou utilizando um procedimento em determinada situação; (4) analisar, desmembrando o material em partes constituintes, para detectá-lo como as partes relacionadas que firmam uma estrutura geral ou representam um propósito; (5) sintetizar, fazer julgamentos embasados em critérios e padrões, por meio de verificação e crítica; (6) criar, juntar os elementos conhecidos para que formem um produto original.

A estrutura bidimensional da taxonomia revisada passou a ser explorada, por Anderson e Krathwohl (2001), a partir da associação entre as dimensões do processo cognitivo: (1) dimensão do conhecimento, (2) fatos, (3) conceitos, (4) processos e (5) meta-cognitivo) e o grau que o estudante considera que adquiriu de conhecimento - lembrar, entender, aplicar, analisar, avaliar ou criar.

Quanto ao domínio afetivo, os objetivos educacionais descrevem as mudanças relacionadas com interesse, atitudes e valores, enfatizando o sentimento e emoção, em um grau de aceitação ou rejeição, expressos como interesses (Bloom et al., 1977). Assim, os objetivos educacionais resultantes desse domínio referem-se ao desenvolvimento de uma atitude de confiança — no poder da razão e métodos de experimentação e discussão; atitude autocrítica inteligente - relacionada com a própria expressão afetiva e comunicação escrita (Bloom et al. 1977) como também diz respeito aos sentimentos e direitos dos demais; posse de fontes profundas de sentimentos e afetos - manifestados por meio de seu contentamento e descontentamento; interesse pela leitura; e, por fim, capacidade de apreciação de uma música (Bloom et al., 1977). 
Essa internalização é a principal ferramenta de classificação, a qual apresenta um dualismo da mente-corpo, definida como um processo pelo qual o objeto de informação é transferido de um estado ou localização externo, para um interno (Morshead, 1965).

As categorias do domínio afetivo são descritas como níveis sucessivos, que, de acordo com Bloom et al. (1977), são representados pela: (1) receptividade: processo da receptividade do sujeito, a partir da tomada de consciência, ele sente um estímulo que atrai sua atenção, (2) resposta: refere-se à forma regular de responder ao seu consentimento, à disposição e à satisfação em responder, (3) valorização: Condição de sustentar, aceitar, ter preferência e compromisso por um valor, (4) organização: organização dos valores atribuídos a um sistema, e (5) caracterização: é o ponto em que o sujeito responde de forma muito coerente, caracterizado por um conjunto completo de valores, que o permite revisar novas evidências e modificar suas atitudes. O domínio afetivo é utilizado para analisar quando o indivíduo toma consciência dos estímulos recebidos e, a partir deles, inicia o comportamento afetivo, que é configurado segundo o contexto em que ocorre (Bloom et al., 1977). Este domínio serviu de base para a verificação, nesta pesquisa, da satisfação (motivação) do estudante quanto às técnicas utilizadas. Uma vez que a motivação é responsável por despertar o interesse do estudante e o seu envolvimento (compromisso) com a aprendizagem, é preciso que o docente identifique estratégias apropriadas que proporcionem o aumento da motivação (Ames, 1990). Assim, o cenário de sala de aula pode ser estimulado por estratégias que proporcionem um aprimoramento de habilidades, valores e integração social dos estudantes (Parellada \& Rufini, 2013).

A satisfação é tida como um instrumento capaz de avaliar a qualidade e a eficácia da educação, pois, esta informação contribui para que as universidades possam, por meio dessas medidas, melhorar seus serviços e, consequentemente, sua qualidade Hussain, Jabbar, Hussain, Rehman e Saghir (2014). A qualidade da educação é definida como um conjunto composto pelas atitudes desenvolvidas pelos estudantes, diante dos conteúdos apresentados e pelo compromisso dos estudantes e dos professores, incluindo a satisfação do estudante e o rendimento acadêmico (Bertolini, 2007). Além da satisfação de o estudante corroborar o seu bem-estar, a motivação pode proporcionar mudanças no ambiente de aprendizagem (Lens, Matos \& Vansteenkiste, 2008). Dessa forma, a proposta deste estudo, quanto à satisfação, foi verificar se o método de caso possui potencial para motivar os estudantes.

\subsection{Estudos anteriores}

Santos, Gaspari e Marques (2016) realizaram um levantamento bibliométrico sobre estudos de metodologias de ensino em Contabilidade. Os achados indicam que os estudos na área da educação em Contabilidade ainda são embrionários, mas estão em ascensão. Os autores listam alguns métodos utilizados na área, como o método de caso e a aprendizagem baseada em problemas, além de indicar alguns autores e técnicas aplicáveis à Contabilidade.

A pesquisa ação realizada por Rios (2011) propôs aplicar a técnica de método de caso para o ensino da Contabilidade, na disciplina Análise das Demonstrações Contábeis, no curso de Ciências Contábeis, de uma instituição de ensino superior paulista, com o objetivo de verificar a contribuição do método para o ensino da Contabilidade. A aplicação do método ocorreu durante uma aula expositiva, na qual o docente apresentou o caso. Na aula seguinte, os estudantes debateram o caso no grande grupo e, na sequência, foi realizada apresentação dos grupos em sala de aula. Posteriormente, foi realizada uma aula de avaliação, e os resultados foram apurados por meio da aplicação de um questionário e da aplicação de prova, que, segundo o autor, apontaram que o método contribuiu para o desenvolvimento de habilidades e confiança dos estudantes, por intermédio de sua participação mais ativa na aprendizagem (RIOS, 2011). 


\section{Procedimentos metodológicos}

Esta pesquisa destinou-se a aplicar uma técnica de ensino ativa - método de caso complementarmente à aula expositiva e à resolução de exercício, a um mesmo grupo de alunos (intacto sem seleção), em uma turma de Ciências Contábeis, na disciplina Estrutura das Demonstrações Contábeis do $4^{\text {a }}$ semestre, durante o primeiro semestre de 2018, de uma Instituição Federal de Ensino Superior (Ifes), em função da acessibilidade à universidade. A turma pesquisada possuía um total de 42 estudantes matriculados, em que 35 participaram do experimento.

O estudo configura-se como um quase experimento, que é realizado para tratamentos com os mesmos sujeitos, analisando-os antes e depois da intervenção (Martins \& Theóphilo, 2016). Nesta pesquisa, aplicou-se uma técnica experimental aos mesmos sujeitos, sem controlar as variáveis, que, de acordo com Campbell e Stanley (1963), é um procedimento de coleta de dados em que o investigador não tem o controle total sobre os estímulos experimentais e pode ser utilizado a um mesmo grupo.

O design a ser realizado durante o quase experimento utilizou, para observação dos dados, os níveis de desenvolvimento apresentados na Taxonomia de Bloom (domínio cognitivo e afetivo), analisados nas fases de pré-teste (após a aula expositiva, mais resolução de exercício) e pós-testes (após o uso do tratamento/técnica experimental). A aplicação do método de caso foi utilizado no ensino do conteúdo da Demonstração do Resultado (D.R), após aula expositiva sobre o assunto (conceitos, objetivos e estrutura), seguida de uma avaliação de conteúdo, por meio de um questionário. Posteriormente, o método de caso foi aplicado por meio de uma D.R com problemas estruturais, contendo um caso (real).

O método de caso é uma técnica que tem o foco na experiência, ou seja, se concentra em um caso específico, com a intenção de estimular a participação do aluno, pela análise e decisões propostas durante a ação, proporcionando o desenvolvimento das habilidades do aluno em analisar, julgar e tomar decisões (Hassler, 1950).

Quanto à avaliação, o desenvolvimento da aprendizagem (cognitivo) foi realizado em dois momentos: após a aula expositiva e resolução de exercício, para verificar o desenvolvimento cognitivo alcançado; e ao término da aplicação do método de caso, utilizada para identificar se o uso da técnica complementar influenciou no nível de desenvolvimento cognitivo alcançado, tendo base na Taxonomia de Bloom. Já a avaliação do Domínio afetivo aconteceu após a aplicação da técnica experimental para verificar a satisfação e a avaliação do estudante com cada técnica aplicada. Para avaliação dos dados, foram realizadas categorizações, de acordo com o domínio cognitivo e afetivo, apresentados por Bloom et al. (1977), para classificar e analisar o conteúdo apresentado nos questionários realizados, buscando-se entender o efeito no desempenho e na satisfação.

O quase experimento foi realizado por meio da utilização de uma técnica de ensino, utilizada de forma complementar a explicação do conteúdo trabalhado na aula expositiva mais a resolução de exercício, em uma turma com 42 estudantes matriculados. No entanto, cabe salientar que, para efeito desta pesquisa, foram considerados somente os 35 que participaram de todas as avaliações realizadas, tendo em vista a intenção de acompanhar o desenvolvimento cognitivo e afetivo dos estudantes.

Historicamente, a disciplina na qual foi aplicado o quase experimento possui alto índice de reprovação (em média, mais de 50\%) e, consequentemente, apresenta estudantes que estão repetindo-a mais de uma vez. Desse modo, o número de desistências e ausências nas aulas é grande. Esse fator foi percebido nas avaliações realizadas, ocasião em que se constatou oscilação da quantidade de alunos participantes. Não houve resistência ou desconforto com a aplicação do quase experimento, pelo contrário, ao ficarem sabendo da proposta de aplicação, os estudantes foram receptivos e ficaram motivados.

A dinâmica para aplicar as avaliações, quanto ao desenvolvimento cognitivo, foi desenvolvida em dois momentos: após a realização da aula expositiva mais a resolução de exercícios, e após a aplicação da técnica, com a intenção de comparar os resultados obtidos através de uma técnica e outra. 
Para identificar o nível de desenvolvimento cognitivo alcançado pelos estudantes, conforme indicado por Anderson e Krathwohl (2001), considerou-se que o estudante atingiu o nível desejável naquelas situações em que a resposta ao questionamento realizado foi elaborada de maneira correta e completa, independente das palavras utilizadas (ditas conforme professor/legislação). Quando o estudante respondeu em parte ao questionamento realizado, considerou-se que, parcialmente, atingiu determinado nível; e quando ele não respondeu ou respondeu de forma errada, considerou-se que ele não atingiu o nível desejado.

Para a realização das avaliações cognitiva e afetiva, foram elaborados instrumentos de análise, aplicados na forma de questionário, embasados na Taxonomia de Bloom, que serviram de base para a verificação dos resultados obtidos - os quais foram dispostos em tabelas, evidenciando os níveis de desenvolvimento cognitivo e afetivo alcançados em cada momento e em cada técnica utilizada (aula expositiva + resolução de exercício e o método de caso).

A aplicação do método de caso foi desenvolvida em três etapas (Leal, Medeiros \& Ferreira, 2017). A primeira etapa ocorreu a partir de um estudo individual por parte dos estudantes, que deviam fazer uma leitura inicial e atenta do caso, com intenção de se familiarizar com o conteúdo apresentado; na segunda, foi realizada uma leitura mais atenta, focada nos detalhes, analisando aqueles mais importantes, com a intenção de identificar o problema. Posteriomente, foram realizadas discussões em pequenos grupos, com o intuito de apurar a elaboração do caso. A partir desse momento, foram sugeridas bibliografias complementares, realizando-se uma troca de ideias com os estudantes, a partir de situações já vivenciadas ou estudadas; e, por fim, foi realizada uma apresentação dos grupos com propostas de solução, que foram debatidas em aula.

O roteiro seguido para aplicação do método de caso foi o indicado por Leal, Medeiros e Ferreira (2017): (1) Planejamento (ocorre antes da aula, este momento é destinado à escolha do caso e do material para leitura, à preparação da aula e do plano de ensino); (2) Apresentação do caso (disponibilização do material bibliográfico, separação dos grupos, análise do caso e busca de solução); (3) Apresentação e discussão (dos argumentos levantados); (4) Conclusão (finalização das discussões, avaliação da participação dos estudantes, aplicação de avaliação e autoavaliação do método bem como avaliação da aprendizagem, por meio de questionário).

Quanto ao objetivo do método, este foi trabalhar os conceitos, objetivos e a estrutura da Demonstração do Resultado, proporcionando ao aluno: entrar em contato com situações reais e possíveis em busca da solução de um problema; desenvolver a habilidade de trabalhar em equipe; e analisar problemas e propor soluções (Leal, Medeiros \& Ferreira, 2017).

A proposta de aplicação da técnica de método de caso foi apresentada aos estudantes, por meio de Power Point, indicando seu conceito, benefícios, objetivo educacional, forma de aplicação e de avaliação, conforme as etapas demonstradas na Figura 1.

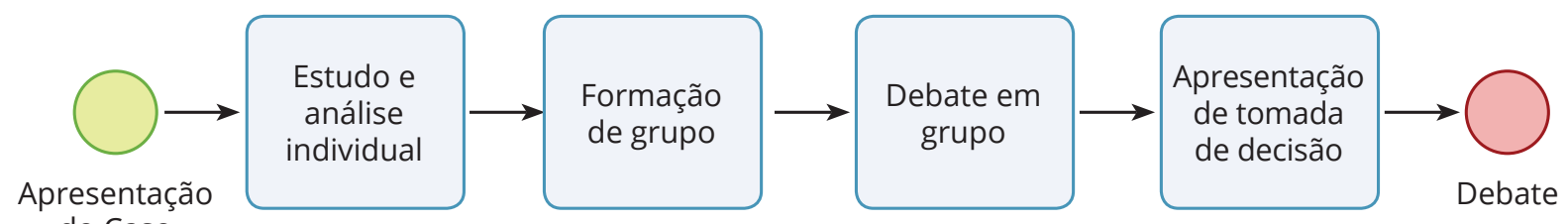
do Caso

Figura 1. Etapas do Método de Caso

Fonte: elaboração própria, com base em Leal, Medeiros e Ferreira (2017). 
As etapas ilustradas na Figura 1 evidenciam os passos de desenvolvimento do método de caso, detalhando sua aplicação, conforme proposto por Leal, Medeiros e Ferreira (2017). Desse modo, ao término da apresentação sobre a técnica, iniciou-se sua aplicação, por meio da entrega aos estudantes de uma Demonstração de Resultado real - a qual se apresentava de forma desestruturada e com um elemento faltante (um valor) - , para que o estudante calculasse o resultado, caracterizando a primeira etapa de desenvolvimento do método de caso. Foram utilizadas duas demonstrações de empresas conceituadas e populares do ramo de vestuário e acessórios. Cada estudante recebeu uma demonstração de forma aleatória e individual, contendo uma letra, por exemplo, Método de Caso (A) e deveria reestruturá-la e calcular o valor não informado.

No total, existiam 6 demonstrações diferentes, distribuídas aleatoriamente entre os estudantes, contendo a indicação de uma letra (A, B, C, D, E, F), para que, após a resolução individual, os estudantes formassem os grupos com base nesta informação. Foram formados 6 grupos, os quais debaterem e buscaram solucionar a questão solicitada, conforme uma das proposições utilizadas: "Analise a situação presente da empresa partindo da demonstração elaborada individualmente, e depois compare com uma nova situação, em que a despesa com vendas deva ser igual a zero".

Com base no caso apresentado, cada grupo deveria realizar uma nova reestruturação da demonstração e comparar ambas as situações, buscando identificar quais seriam os reflexos dessa mudança nas demais contas da estrutura e realidade da empresa. Na sequência, deveriam debater sobre o reflexo das mudanças propostas e apresentar a tomada de decisão, indicando se a nova mudança deveria, ou não, ser realizada pela empresa. Cada grupo defendeu suas ideias, com base nos conceitos trabalhados, tendo sido promovido um intenso debate com toda turma. A aplicação recém-descrita, foi realizada em quatro aulas de 50 minutos cada.

\section{Análise e discussão dos resultados}

As avaliações realizadas para análise do desenvolvimento cognitivo e afetivo do método de caso foram realizadas por meio da aplicação de questionários, que serviram para identificar o nível alcançado pelos estudantes em cada momento avaliado e verificar se o uso da técnica foi capaz de influenciar o nível cognitivo e afetivo atingido pelos estudantes. Para a realização dessa análise, foi elaborado um instrumento de avaliação, contendo as questões que permitiram verificar cada nível proposto pela Taxonomia de Bloom, quanto ao Domínio Cognitivo, conforme a Tabela 1.

Tabela 1

Instrumento de Avaliação Cognitiva - D.R

\begin{tabular}{|c|c|c|}
\hline \multirow{2}{*}{$\begin{array}{l}\text { Dimensão } \\
\text { Cognitiva }\end{array}$} & \multicolumn{2}{|r|}{ Dimensão do conhecimento } \\
\hline & Fatos e Termos & Conceitos (estrutura) e processos \\
\hline Lembrar & $\begin{array}{l}\text { Q1. Defina o que é o resultado } \\
\text { líquido do período? }\end{array}$ & $\begin{array}{l}\text { Q2. Descreve onde a empresa deve classificar a conta resultado } \\
\text { da equivalência patrimonial na estrutura da Demonstração do } \\
\text { Resultado? }\end{array}$ \\
\hline Entender & $\begin{array}{l}\text { Q1.1 Explique o que representa o } \\
\text { resultado líquido do período para } \\
\text { empresa? }\end{array}$ & $\begin{array}{l}\text { Q2.2 Interprete: Caso a empresa tenha resultado negativo, qual o } \\
\text { reflexo nos impostos sobre o lucro? }\end{array}$ \\
\hline Aplicar & $\begin{array}{l}\text { Q5. Elabore a Demonstração do } \\
\text { Resultado. }\end{array}$ & Q5. Elabore a Demonstração do Resultado. \\
\hline Analisar & & $\begin{array}{l}\text { Q3. Comparando os resultados da empresa nas etapas } 1 \text { e } 2 \\
\text { da atividade individual e em grupo, identifique qual apresenta } \\
\text { melhor situação e capacidade de crescimento }\end{array}$ \\
\hline Sintetizar & & $\begin{array}{l}\text { Q.4 Proponha soluções para melhorar o resultado da empresa } \\
\text { que teve o pior resultado do período. }\end{array}$ \\
\hline Criar & & Q3.1. Justifique a resposta da questão 3. \\
\hline
\end{tabular}

Fonte: elaboração própria, com base em Bloom et al (1977) e Krathwohl (2002). 
Com base no instrumento descrito na Tabela 1, aplicou-se a avaliação cognitiva nos 35 estudantes que participaram das duas avaliações propostas no método de caso.

$\mathrm{Na}$ interrogação (Q.1), buscou-se verificar a lembrança de fatos e termos sobre a demonstração do resultado, identificando a capacidade de o estudante recordar os termos técnicos e seu significado para a contabilidade, conforme indicado por Bloom et al.(1977). Identificou-se que $20 \%$ dos estudantes alcançaram o nível "Lembrar" de forma completa e $80 \%$ de forma parcial. Logo, nenhum estudante deixou a questão em branco ou respondeu de maneira errada. Infere-se que os estudantes, de forma geral, conseguiram recordar o assunto estudado.

Ainda no nível "Lembrar", na questão (Q.2), buscou-se identificar a compreensão dos estudantes quanto aos fatos específicos trabalhados na D.R, conforme recomendam Bloom et al. (1977), quanto ao conhecimento de conceitos, estruturas e processos. Esse questionamento revelou que 17,14\% dos estudantes responderam de forma correta e completa a essa questão, 20\% de maneira parcial; e 62,86\% não alcançaram este nível, sugerindo maior dificuldade de compreensão dos conceitos, estruturas e processos trabalhados.

Quanto ao nível "Entender", foi questionado, na sequência da questão (Q.1), quanto a fatos e termos, com a intenção de verificar se o estudante era capaz de explicar o que entendeu sobre o assunto solicitado. Neste nível, $48,57 \%$ dos estudantes responderam de forma completa, 22,86\% atingiram parcialmente e $28,57 \%$ não alcançaram o nível "Entender", sinalizando que a maioria dos estudantes, em parte ou de forma total, conseguiu entender os fatos e os termos trabalhados. Explorando ainda o nível entender quanto ao conhecimento de conceitos, estruturas e processos, foi solicitado aos estudantes que interpretassem o reflexo do resultado negativo nos impostos, conforme (Q.2.2). Deste questionamento, 85,71\% estudantes atingiram o nível "Entender", 11,43\% parcialmente atingiram e apenas 2,86\%, ou seja, um estudante não atingiu, apontando que o entendimento dos conceitos, estruturas e processos ocorreu de forma mais ampla do que aquele atingido pelos fatos e termos.

Quanto ao nível aplicar, foi solicitado que os estudantes elaborassem uma Demonstração do Resultado. Porém, como o exercício foi resolvido em aula, antes da entrega por parte dos estudantes, seu resultado não retrataria o desenvolvimento realizado pelo estudante, por este motivo não fez parte desta análise.

No nível "Analisar", foram verificados, por meio da apreciação por parte dos estudantes, dois exercícios realizados pelo professor (como resolução de exercício), os quais apresentaram duas Demonstrações de Resultado, de dois anos consecutivos, de duas empresas distintas. Uma empresa apresentava lucro e a outra, prejuízo, com intenção de verificar a capacidade de os estudantes reconhecerem pressupostos explícitos, estrutura e funcionamento da D.R, portanto não havia uma única resposta correta. Solicitou-se aos estudantes, com base nestas demonstrações, que buscassem analisar qual delas possuía melhor situação e capacidade de crescimento, conforme (Q3). Apenas 2,86\% dos estudantes analisaram a questão relacionando seus argumentos com os conceitos estudados, enquanto os demais $97,14 \%$ analisaram parcialmente a questão, expondo apenas a opinião, sem reconhecer pressupostos explícitos (por meio de análise dos dados, de maneira comparativa com a teoria, distinguindo formas e elementos de uma empresa para outra, etc.). Segundo Bloom et al. (1977), este nível permite identificar a compreensão dos fatos solicitados, apoiando-se nos fatos e normas, apresentando uma sustentação para sua resposta.

No nível "Sintetizar", continuou-se trabalhando em cima das duas demonstrações utilizadas no exercício desenvolvido pelo professor, solicitando a elaboração de uma proposta para melhorar o resultado da empresa, conforme (Q.4). Nesta questão, a ideia foi verificar a habilidade do estudante para desenvolver argumentos que defendessem sua solução embasada nos conteúdos estudados. A intenção do questionamento foi verificar se o estudante conseguiria fazer justificativas (associações) com bases nas informações que tinha, por meio dos conteúdos estudados. O resultado apontou que $97,14 \%$ dos estudantes atingiram parcialmente o nível sintetizar", em função de não desenvolver argumentos baseados nos conteúdos estudados, e 2,86\% apresentaram uma resposta fora do contexto analisado (respostas sem argumento lógica/teórica), demonstrando a dificuldade relacionada a este nível, que requer, segundo Bloom et al. (1977), a realização de um exame dos fatos, por parte do aluno, apontando uma descrição prática, como a indicação de causa e efeitos para sua argumentação. 
Para analisar o último nível, a capacidade de o estudante "Criar" a partir dos conceitos trabalhados, relacionando suas críticas às normas, solicitou-se aos estudantes que justificassem a resposta dada quanto à questão (Q.3) sobre qual empresa (do exercício da D.R) apresentava melhor situação e capacidade de crescimento, conforme (Q3.1). Nesse quesito, nenhum estudante apresentou justificativa ou argumento para defender sua resposta. Este degrau, proposto por Bloom et al. (1977), impõe que o estudante apresente um juízo pautado em argumentos particulares, desenvolvidos, anteriormente, em cada nível, defendendo uma proposta que contenha conceitos que recorda, entende, aplica e é capaz de sintetizar. Assim, o nível cognitivo atingido pelos estudantes na totalidade, com base na aula expositiva e resolução de exercícios, sobre o conteúdo da Demonstração de Resultado, apresenta-se na Figura 2.

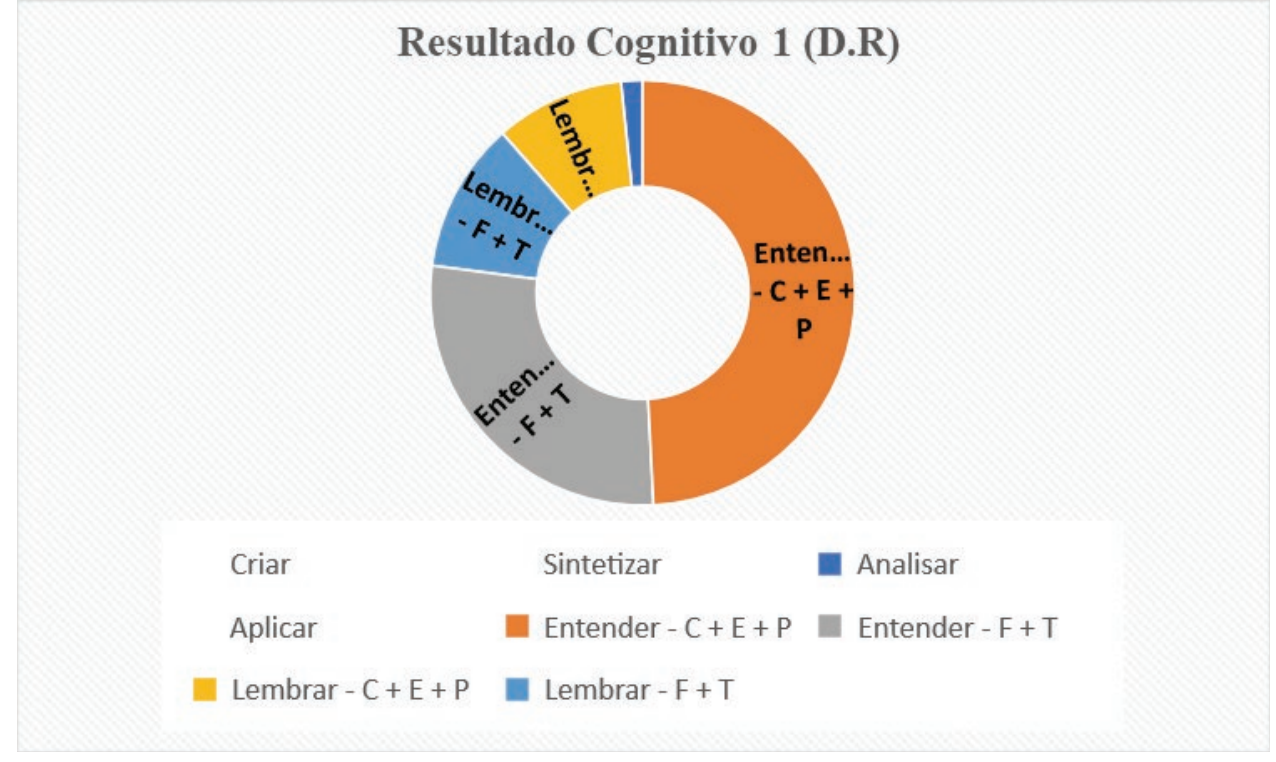

Figura 2. Avaliação Cognitiva - Aula expositiva + R. E - (D.R)

Fonte: dados da pesquisa.

Destaca-se, nesses resultados, que a maioria dos estudantes atingiu ou parcialmente atingiu o nível "Lembrar", quando questionados com assuntos referentes a fatos e termos $(\mathrm{F}+\mathrm{T})$; já quando o assunto tratou de conceitos, estruturas e processos (C+E+ P), 62,86\% não atingiram este nível. Enquanto, no nível "Entender", este resultado foi diferente, em ambos os casos, a maioria atingiu ou parcialmente o nível analisado. Percebe-se que nenhum estudante conseguiu, a partir dos conhecimentos desenvolvidos, atingir o nível "Criar" - o mais complexo e difícil de alcançar, segundo Bloom et al. (1977).

Quanto à análise de satisfação do estudante com a aula expositiva seguida da resolução de exercício sobre a D.R, elaborou-se um instrumento de avaliação, com base no domínio afetivo da Taxonomia de Bloom, conforme Tabela 2. 
Tabela 2

Instrumento de Avaliação Afetivo - Aula expositiva + R.E - (D.R)

\begin{tabular}{|c|c|}
\hline Níveis & Auto avaliação \\
\hline Receber & $\begin{array}{l}\text { Q2. Acredita que a aula expositiva mais a resolução de exercícios ajudaram a melhorar o } \\
\text { entendimento do conteúdo? } \\
\begin{array}{ll}\text { (_) Sim } & \text { (_) Não }\end{array}\end{array}$ \\
\hline Responder & $\begin{array}{l}\text { Q1. Atribua uma nota a aplicação da aula expositiva + Resolução de exercícios: } \\
\text { (_) } 5 \text { - Muito satisfeito (_) 4- Satisfeito (_) } 3 \text { - Parcialmente satisfeito } \\
\text { (_) 2- Insatisfeito (_) } 0 \text {-Totalmente Insatisfeito }\end{array}$ \\
\hline Valorizar & $\begin{array}{l}\text { Este item foi utilizado após a aplicação da técnica método de caso, com a intenção de verificar a } \\
\text { preferência do estudante entre a aula expositiva + resolução de exercício ou o método de caso. }\end{array}$ \\
\hline Organizar & Este item se refere a organizar as preferencias. Este elemento não foi utilizado no experimento. \\
\hline Caracterizar & $\begin{array}{l}\text { Q3. Gosta de participar de atividades em grupo? } \\
\begin{array}{ll}\text { (_) Sim } & \text { (_) Não }\end{array}\end{array}$ \\
\hline
\end{tabular}

Fonte: elaboração própria, com base em Bloom et al. (1977).

Esses questionamentos foram utilizados com a intenção de compreender como o estudante recebeu e respondeu ao estímulo realizado a partir da estratégia de ensino, assim como possibilitou a compreensão de como o estudante organiza suas preferências e por meio do item "Caracterizar" pode identificar-se a modificação no seu comportamento.

Os resultados da autoavaliação (Q.2) revelaram que 100\% dos estudantes acreditam que a aula expositiva mais a resolução de exercício ajudaram a compreender melhor o conteúdo sobre a D.R. Esse nível releva a consciência do estudante frente a uma situação em que, segundo Bloom et al. (1977), deva avaliar a característica do estímulo, percebendo-a como uma atividade concluída.

Quanto à satisfação, verificada no nível "Responder" (Q.1), 94,24\% dos alunos ficaram satisfeitos com a forma de explanação do conteúdo e 5,71\% parcialmente satisfeitos, indicando, conforme Bloom et al. (1977), a disposição apresentada pelos estudantes em participar da atividade determinada. Segundo Bertolini (2007), a satisfação pode indicar o compromisso do estudante frente ao seu aprendizado e influenciar no seu rendimento.

O elemento "Caracterizar" (Q.3), segundo Bloom et al. (1977), está associado à convicção do estudante frente a uma situação, nesse caso, utilizado para identificar o comportamento do estudante diante da sua participação em atividades de grupo. Esse nível revelou que 77,14\% dos estudantes gostam de participar de atividades em grupo, contra 22,86\% que disseram não gostar. A Figura 3 ilustra os resultados alcançados na totalidade, através da avaliação afetiva. 


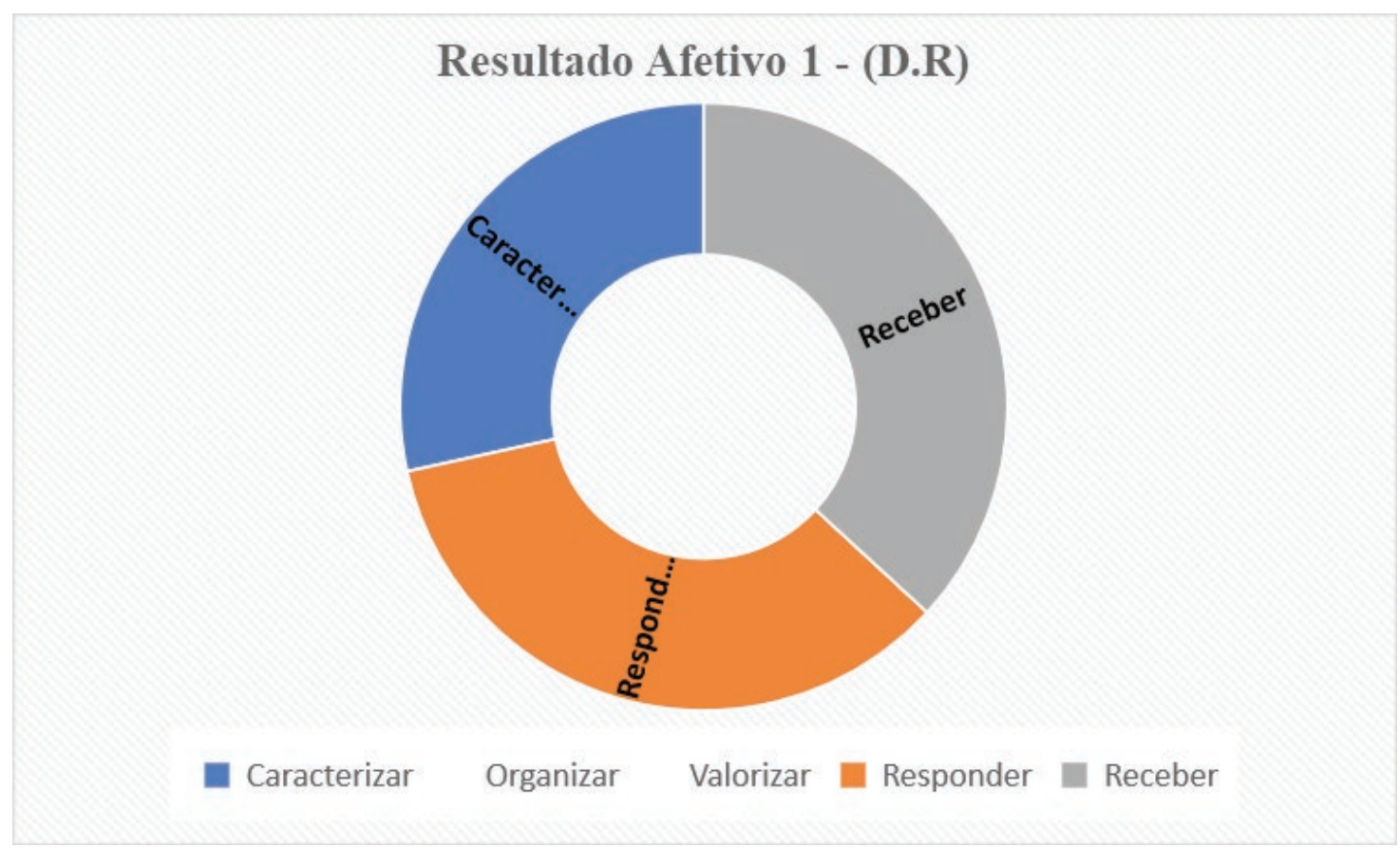

Figura 3. Avaliação Afetiva - Aula expositiva + R. E (D.R)

Fonte: dados da pesquisa.

Os resultados evidenciados na Figura 3 sintetizam as atitudes alcançadas e percebidas pelos estudantes frente ao estímulo realizado pela aula expositiva e resolução de exercício, para o estudo da demonstração do resultado, evidenciando que os estudantes acreditam na capacidade de a estratégia ajudar na compreensão do conteúdo. A maioria ficou satisfeita com a experiência, indicando que existiu comprometimento com a atividade, e 77,14\% afirmam gostar de participar de atividades em grupo.

Quanto à segunda avaliação realizada após a aplicação do método de caso, as questões utilizadas para avaliar o desenvolvimento cognitivo foram iguais ou similares àquelas realizadas na avaliação anterior (Tabela 1). Nesse sentido, os resultados revelam que dos 35 estudantes que participaram do método de caso, quanto ao nível "Lembrar" de fatos e termos, 25,71\% responderam à questão (Q1) de forma completa, atingindo, assim, o nível, enquanto 71,43\% atingiram parcialmente e 2,86\% não atingiram o nível. Esse resultado é próximo ao atingido pela aula expositiva mais a resolução de exercícios, que apontou terem lembrado de fatos e termos, de forma completa $20 \%$, e, parcialmente, $80 \%$.

Quanto aos conceitos, estruturas e processos, ainda no nível "Lembrar", percebe-se que os resultados alcançados com a técnica foram mais significativos do que a avaliação anterior, pois $22,86 \%$ atingiram o nível e 74,29\% parcialmente atingiram. Já, no caso anterior, esses resultados foram respectivamente, 17,14\% e 20\%, indicando que o uso da técnica, neste assunto e nível, influenciou o desenvolvimento cognitivo. Já os resultados verificados nos níveis "analisar", "sintetizar" e "criar", foram similares ao resultado avaliado após a aula expositiva mais a resolução de exercícios.

No momento um, os níveis analisar e sintetizar foram atingidos parcialmente por $97,14 \%$ dos estudantes, e o nível criar não foi alcançado por nenhum estudante. No entanto, houve variância entre um estudante que atingiu o nível "analisar" anteriormente e um que atingiu o "sintetizar" com o método de caso. Assim, demonstra-se o resultado do desenvolvimento cognitivo atingido na totalidade (Figura 4). 


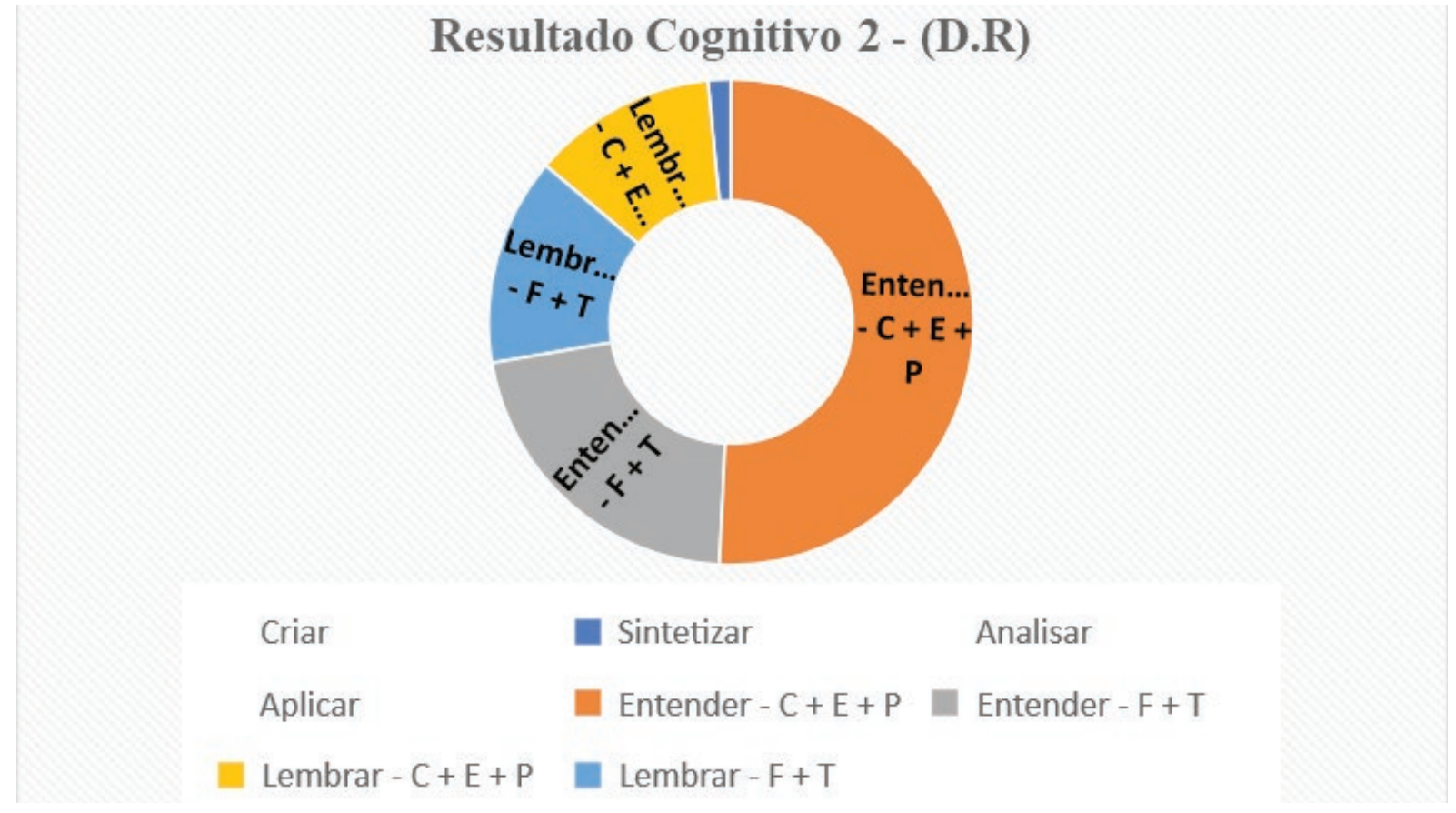

Figura 4. Avaliação Cognitiva - Método de Caso

Fonte: dados da pesquisa.

Analisando-se o método de caso, técnica que foca na experiência e busca estimular a tomada de decisão, conforme indica Hassler (1950), percebe-se que o objetivo educacional foi atingido. Os estudantes experienciaram a realização de tomada de decisão, já que propuseram manter, ou não, a nova situação indicada pelo exercício proposto. Quanto ao desenvolvimento cognitivo, apesar de não terem atingido o nível de "Criar", percebe-se que a técnica nos níveis "Lembrar e Entender" foi capaz de influenciar, positivamente, o desenvolvimento cognitivo dos estudantes, pois aumentou o percentual de estudantes que, nestes níveis, compreenderam melhor o conteúdo.

Desse contexto, infere-se que houve uma transformação na estrutura mental dos estudantes, conforme indica Piaget (1970), verificada pela comparação dos resultados da avaliação $1 \mathrm{com}$ a 2, antes e após a aplicação do método de caso, quanto à evolução dos estudantes que utilizaram da memória (adquirida na aula expositiva ou antes) para construir um conceito (atingir o nível entender).

Assim, segundo Piaget (1970), nesses casos, os estudantes estão assimilando conhecimento, pois se utilizam dos conhecimentos prévios para construir novas estruturas, permitindo apontar, em virtude da avaliação inicial realizada quanto ao nível "Entender", que os estudantes, neste elemento, precisaram acomodar novos conhecimentos, os quais não existiam anteriormente, portanto realizaram uma transformação na sua estrutura cognitiva.

A análise quanto à satisfação dos estudantes com a aplicação do método de caso foi verificada por meio dos questionamentos realizados na autoavaliação, buscando identificar as atitudes desenvolvidas, com base na Taxonomia de Bloom, conforme Tabela 3. 
Tabela 3

Instrumento de Avaliação Afetiva - Método de Caso

\begin{tabular}{|c|c|}
\hline Níveis & Questionamentos \\
\hline Receber & $\begin{array}{l}\text { Q2. Acredita que o método de caso ajudou a melhorar o entendimento do conteúdo? } \\
\text { (_) } \operatorname{Sim}\left(\_\right) \text {Não }\end{array}$ \\
\hline Responder & $\begin{array}{l}\text { Q1. Atribua uma nota a aplicação do método de caso: } \\
\text { (_) } 5 \text { - Muito satisfeito (_) } 4 \text { - Satisfeito (_) } 3 \text { - Parcialmente satisfeito } \\
\text { (_) } 2 \text { - Insatisfeito (_) } 0 \text { - Totalmente Insatisfeito }\end{array}$ \\
\hline Valorizar & $\begin{array}{l}\text { Q4. Qual técnica aplicada você tem preferência? } \\
\text { (_) Aula expositiva + Resolução de exercício (_) Método de caso } \\
\text { (_) Não tenho preferência }\end{array}$ \\
\hline Organizar & Não utilizado nesta pesquisa. \\
\hline Caracterizar & $\begin{array}{l}\text { Q.3. Gostou de participar da atividade em grupo, considerando a troca de ideias e } \\
\text { colaboração dos colegas? } \\
\text { (_) Sim (_) Não }\end{array}$ \\
\hline
\end{tabular}

Fonte: elaborado com base em Bloom et al (1977).

Esses questionamentos tinham a intenção de analisar como o estudante recebeu o estímulo realizado por meio do Método de Caso (Q.1), respondeu a ele (Q.2), valorizou suas preferências (Q.4) e modificou, ou não, sua atitude (Q.3) frente à participação em uma atividade de grupo. Para tal, o instrumento proporcionou analisar se o estudante que disse não gostar de participar deste tipo de atividade revisou as evidências, tais como os benefícios da técnica, e, também, modificou suas atitudes, passando a gostar.

Os resultados do domínio afetivo revelaram, quanto ao nível "Receber" (Q.2), que $100 \%$ dos estudantes acreditaram que o método de caso ajudou a compreender melhor o conteúdo sobre a demonstração do resultado, assim como ocorreu na avaliação para aula expositiva e resolução de exercício. O mesmo se pode dizer da satisfação. Os resultados obtidos são idênticos aos alcançados pela aula expositiva e resolução de exercícios da D.R, visto que 94,29\% ficaram satisfeitos com a técnica e 5,71\% parcialmente satisfeitos (Q.1).

Já, na avaliação quanto à caracterização (Q.3), percebe-se uma leve mudança de atitude dos estudantes, pois $88,57 \%$ afirmaram ter gostado de participar da atividade contra $11,43 \%$ que não gostaram. Anteriormente, na autoavaliação realizada após a aula expositiva e resolução de exercícios, esses resultados foram, respectivamente, $77,14 \%$ e $22,86 \%$, evidenciando que, após participarem de uma atividade em grupos, alguns estudantes modificaram suas atitudes, passando a gostar da estratégia.

Quando questionados a respeito da preferência (Q.4) entre a aula expositiva, acompanhada da resolução de exercício, e o método de caso, os estudantes que atingiram o nível "Valorizar" foram aqueles que tiveram a preferência pelo método de caso, logo 42,86\% dos estudantes, enquanto 8,57\% atingiram parcialmente o nível, pois apontaram ter gostado das duas técnicas de formas iguais, e 48,57\% indicaram a preferência pelo método tradicional.

Diante da análise do domínio afetivo, é possível concluir que os estudantes ficaram satisfeitos com a técnica, indicando que o método de caso pode ser uma estratégia motivadora para os estudantes, já que proporcionou satisfação. Esse resultado é compatível com o estudo de Rios (2011), que utilizou o método de caso na disciplina Análise das Demonstrações Contábeis, revelando que a técnica contribui com o desenvolvimento e motivação dos estudantes, tornando-os mais ativos e responsáveis pela aprendizagem.

Além desses fatores, os apontamentos de Hassler (1950) indicam a necessidade de os estudantes trabalharem com dados incompletos, como os apresentados no método de caso, pois, na vida profissional, eles enfrentam situações em que necessitam analisar atentamente informações que podem estar incompletas. Por esses motivos, segundo o autor, os estudantes acabam aceitando, este tipo de técnica. 


\section{Considerações finais}

O desenvolvimento do conhecimento é defendido por Piaget (1954) como sendo resultado da inteligência, da consciência do sujeito, construído a partir da sua interação com o objeto de estudo, mediante a utilização de esquemas. Esses esquemas, segundo o autor, utilizam estruturas já existentes, proporcionando assimilação do conteúdo, ou criam novas estruturas para interpretar e acomodar uma nova informação. Nesse sentido, o conhecimento é resultado de uma transformação sofrida na consciência do sujeito, diante das experiências vivenciadas por ele. Assim, segundo Becker (1992), o processo educacional deve ser direcionado por meio de processo espontâneo que possibilite essa construção. Dessa forma, considerando que a aprendizagem é vista como uma condição que possibilita a construção de significados, cabe ao docente adotar estratégias que influenciem e proporcionem esta construção (Moreira, 2011). Essas estratégias, por consequência, representam o caminho que o docente utilizará para auxiliar no desenvolvimento intelectual dos estudantes. Portanto, torna-se necessário variá-lo para beneficiar os diversos estilos de aprendizagem.

Assim, analisar o processo de desenvolvimento cognitivo dos estudantes, considerando que o conhecimento é construído, contribui com o processo de ensino e aprendizagem, pois permite ao educador se posicionar como um orientador, que busca encontrar instrumentos que facilitem o processo, estimulando e motivando os estudantes. Esta percepção construtivista proporciona a compreensão dos fatores que influenciam a aprendizagem, assim como, por meio das avaliações cognitiva e afetiva, permite a identificação das dificuldades encontradas no processo e possibilita ao docente rever suas estratégias de ensino e melhorá-las.

Esta pesquisa analisou o desempenho cognitivo alcançado pelos estudantes com a aplicação da técnica de ensino do método de caso. Os achados indicam que a referida técnica, como estratégia complementar, foi capaz de influenciar os níveis de desenvolvimento cognitivo e afetivo alcançado pelos estudantes, não conseguindo proporcionar o alcance na totalidade dos níveis mais complexos (analisar, sintetizar e criar), mas influenciando, significativamente, a aprendizagem dos níveis mais básicos (lembrar, entender). Para classificar as respostas emitidas de forma parcial pelos estudantes, considerou-se que estes atingiram parcialmente os níveis investigados quando responderam em parte as questões, e esse resultado sofreu forte influência no desenvolvimento cognitivo em todos os níveis analisados neste estudo (ampliação no percentual atingido).

Analisando as atitudes desenvolvidas, verificadas pela dimensão afetiva constante na Taxonomia de Bloom, buscou-se compreender a motivação dos estudantes com a aplicação do método de caso. Os resultados encontrados indicam que, de forma geral, os estudantes ficaram satisfeitos com todas as técnicas aplicadas (aula expositiva + resolução de exercício e o método de caso), o que revela que, de forma geral, a aplicação do método de caso é considerada como motivadora pelos discentes. Outras atitudes desenvolvidas pelos estudantes foram o comprometimento com as tarefas propostas, a colaboração, o respeito, a flexibilidade na distribuição de tarefas, o interesse pelas atividades e a troca de experiências. Esse resultado é semelhante ao encontrado Leal e Oliveira (2018), que concluiram que o método de caso contribui com a aprendizagem, com o trabalho em equipe, com a reflexão e a análise crítica.

Assim, os dados levantados nesta pesquisa permitem inferir que o uso do método de caso, como técnica complementar de ensino, contribuiu com o desenvolvimento da aprendizagem superficial, pois ampliou o nível de desenvolvimento mais básico, além de auxiliar na ampliação de todos os níveis cognitivos de forma parcial e proporcionar a motivação nos estudantes.

Este estudo foi desenvolvido considerando que o conhecimento é construído por meio das experiências vivenciadas pelo sujeito e da experimentação de uma técnica de ensino específica; propôs-se avaliar a capacidade de tal técnica influenciar o nível de desempenho cognitivo alcançado pelos estudantes. Os resultados indicam que as experiências proporcionadas auxiliaram na construção dos conhecimentos desenvolvidos, conforme dados encontrados nas avaliações realizadas com base na Taxonomia de Bloom. 
Os achados sugerem que o uso do método de caso, como complemento à aula expositiva e à resolução de exercício, é benéfico para o processo de aprendizagem, visto que proporciona um desenvolvimento cognitivo mais elevado nos estudantes, permitindo aos docentes utilizarem esses dados como um instrumento de análise, diante dos objetivos educacionais que pretendem alcançar, e se sintam estimulados com as possibilidades. Assim, conclui-se que o uso do método de caso contribui com o processo de ensino e aprendizagem. O estudo colaborou, também, com os estudantes, que, por intermédio da aplicação de uma técnica ativa, obtiveram um ambiente de aprendizagem com integração, trabalho em grupo, desenvolvimento da experiência de resolver problemas e tomar decisões, aperfeiçoando a comunicação, a realização de pesquisa, e principalmente, proporcionado um ambiente capaz de melhorar o desenvolvimento cognitivo, trazendo satisfação. A satisfação pode ser um indicador de qualidade. Nesse sentido, sua análise foi fundamental para compreender os processos que precisam ser melhorados, servindo de base para a gestão das Ifes rever os planos e propostas educacionais.

As limitações desta pesquisa estão relacionadas ao fato de ter sido realizada em apenas uma turma, sem poder comparar seus resultados com outra que não sofresse a influência das técnicas aplicadas, permitindo verificar o desenvolvimento proporcionado em ambos os casos. Outro fator limitante foi o tamanho da amostra, que, por se tratar de apenas uma turma, não permite que os dados encontrados sejam generalizados. Como sugestão para pesquisas futuras, recomenda-se a aplicação de um experimento utilizando uma técnica complementar em uma turma e em outra não, e em uma instituição pública e outra privada, para que o efeito do desenvolvimento cognitivo e afetivo possa ser comparado entre as turmas e as Instituições. Outra sugestão é realizar a identificação dos estilos de aprendizagem dos estudantes, permitindo realizar uma seleção de técnicas de ensino condizentes (direcionadas) com a forma de aprender dos estudantes.

\section{Referências}

Ames, C. (1990). Motivation: What teachers need to know. Teachers college record, 91(3), 409-421. DOI $0161-4681 / 90 / 9103 / 409 \$ 1.25 / 0$

Anderson, L. W., \& Krathwohl, D. R. (2001). A taxonomy for learning, teaching, and assessing: a revision of Bloom's taxonomy of educational objectives. New York: Longman.

Barbosa, J. R. A. (2008). A avaliação da aprendizagem como processo interativo: um desafio para o educador. Democratizar, II(1). Recuperado de http://cursos.unipampa.edu.br/cursos/progesus/ files/2011/04/BARBOSA-JRA.-Avalia\%25C3\%25A7\%25C3\%25A3o-da-aprendizagem-comoprocesso-interativo.pdf

Becker, F. (1992). O que é construtivismo. Revista de educação AEC, 21(83), 7-15. DOI UFRGS - PEAD $2009 / 1$

Bertolin, J. C. G. (2007). Indicadores em nível de sistema para avaliar o desenvolvimento e a qualidade da educação superior brasileira. Avaliação, Campinas, 12(2), 309-331. DOI: doi.org/10.1590/S141440772007000200007

Bloom, B. S., Engelhart, M. D., Furst, E. J., Hill, W. H., \& Krathwohl, D. R. (1977). Taxonomía de los objetivos de la educación. Buenos Aires: El Ateneo.

Bloom, B. S., Hastings, J. T., \& Madaus, G. F. (1971). Handbook on formative and sommative evaluation of student learning. New York: McGraw-Hill.

Bordane, J. D., \& Pereira, A. M. (2015). Estratégias de ensino-aprendizagem. 33º ed. Petrópolis: Vozes.

BRASIL, C. D. V. M. (2007). Lei No 11.638, de 28 de dezembro de 2007. Altera e revoga dispositivos da Lei, $(6.404 / 1964)$. 
BRASIL, A. G. D. U., \& da União, C. G (2009). Lei No 11.941, de 27 de maio de 2009. Altera a legislação tributária federal relativa ao parcelamento ordinário de débitos tributários.

Butzke, M. A., \& Alberton, A. (2017). Estilos de aprendizagem e jogos de empresa: a percepção discente sobre estratégia de ensino e ambiente de aprendizagem. REGE-Revista de Gestão, 24(1), 72-84. DOI:https://doi.org/10.1016/j.rege.2016.10.003

Campbell, D. T., \& Stanley, J. C. (1963). Experimental and Quasi-Experimental Designs for Research on Teaching. Palo Alto London: Rand McNally \& Company.

Carneiro, I. M. S. P., Portes, L. F., \& Cavalcante, M. M. D. (2014). O ensinar e o aprender de professores no contexto da educação profissional e tecnológica. Práxis Educacional, 10(17), 289-313. Recuperado de http://periodicos2.uesb.br/index.php/praxis/article/view/791

Guimarães, J. C. F., Severo, E. A., Nobrega, K. C., \& Leone, N. M. C. P. G. (2019). A influência da inovação no ensino, qualidade e comprometimento sobre a retenção de alunos no ensino superior. Revista Gestão Universitária na América Latina-GUAL, 12(1), 249-269. DOI: http://dx.doi.org/10.5007/19834535.2019v12n1p249

Haydt, R. C. C. (2011). Curso de didática geral. São Paulo: Ática.

Hassler, R. H. (1950). The case method of teaching accounting. The Accounting Review, 25(2), 170-172. DOI: https://www.jstor.org/stable/240255

Hessen, J. (2003). Teoria do conhecimento. Tradução de João Vergílio Gallerani Cuter. 2a ed. São Paulo: Martins Fontes.

Hussain, S., Jabbar, M., Hussain,, Z., Rehman, Z., \& Saghir, A. (2014). The Students' Satisfaction in Higher Education and its Important Factors: A Comparative Study between Punjab and AJ\&K, Pakistan. Research Journal of Applied Sciences, Engineering and Technology, 7(1), 4343-4348. DOI:10.19026/ rjaset.7.806

Krathwohl, D. R. (2002). A revision of Bloom's taxonomy: An overview. Theory into practice, 41(4), 212218.DOI: https://doi.org/10.1207/s15430421tip4104_2

Krathwohl, D. R., \& Anderson, L. W. M. C. (2010). Wittrock and the revision of Bloom's Taxonomy. Educational psychologist, 45(1), 64-65. DOI:https://doi.org/10.1080/00461520903433562

Knowles, M. S., Holton III, E. F., \& Swanson, R. A. (2012). The adult learner. Routledge.

Leal, E. A., Medeiros, C. R. O., \& Ferreira, L. V. (2017). In: O uso do método do caso de ensino na educação na área de negócios. Leal, E. A., Miranda, G. J., \& Casa Nova, S. P. C. Revolucionando a sala de aula: como envolver o estudante aplicando as técnicas de metodologias ativas de aprendizagem. São Paulo: Atlas, 93-104.

Leal, E. A., Miranda, G. J., \& Casa Nova, S. P. C. (2017). Revolucionando a sala de aula: como envolver o estudante aplicando as técnicas de metodologias ativas de aprendizagem. São Paulo: Atlas.

Leal, E. A., \& Oliveira, R. L. (2018). O método de estudo de caso aplicado no ensino em cursos de pósgraduação em ciências contábeis. Revista Contemporânea de Contabilidade, 15(35), 69-87. DOI: https://doi.org/10.5007/2175-8069.2018v15n35p69

Lefrançois, G. R. (2016). Teorias da aprendizagem: o que o professor disse. Tradução Solange A. Visconte. São Paulo: Cengage Learning.

Lens, W., Matos, L., \& Vansteenkiste, M. (2008). Professores como fontes de motivação dos alunos: o quê e o porquê da aprendizagem do aluno. Educação, 31(1), 17-20. Recuperado de http://revistaseletronicas. pucrs.br/ojs/index.php/faced/article/view/2752/2100 
Lopes, E. S., \& Carvalho, A. C. F. (2017). Avaliação da Aprendizagem: um Desafio para o Docente. Id on Line Revista de Psicologia, 10(33), 304-319. Recuperado de ISSN 1981-1179 Edição eletrônica em http://idonline.emnuvens.com.br/id

Luckesi, C. C. (2014). Avaliação da aprendizagem escolar: estudos e proposições. São Paulo: Cortez.

Martins, G. A., \& Theóphilo, C. R. (2016). Metodologia da investigação científica para ciências sociais aplicadas. (3 ed.), São Paulo: Atlas.

Moreira, M. A. (2011). Teorias da aprendizagem. (2 ed.) São Paulo: EPU.

Morshead, R. W. (1965). Taxonomy of educational objectives Handbook II: Affective domain. Studies in Philosophy and Education, 4(1), 164-170. DOI:https://doi.org/10.1007/BF00373956.

Morozini, J. F., Cambruzzi, D., \& Longo, L. (2007). Fatores que influenciam o processo de ensinoaprendizagem no curso de Ciências Contábeis do ponto de vista acadêmico. Revista Capital Científico, 5(1), 87-102. Recuperado de http://www.spell.org.br/documentos/ver/32984/fatoresque-influenciam-o-processo-de-ensino-aprendizagem-no-curso-de-ciencias-contabeis-do-pontode-vista-academico/i/pt-br

Oliveira, A. S. B., Pontes, J. N. A. \& Marques, M. A. (2016). O Uso da Taxonomia de Bloom no Contexto da Avaliação por Competência. Revista Pleiade, 10(20), 12-22. Recuperado de https://pleiade. uniamerica.br/index.php/pleiade/issue/view/46

Parellada, I. L., \& Rufini, S. E. (2013). O uso do computador como estratégia educacional: relações com a motivação e aprendizado de alunos do ensino fundamental. Psicologia: Reflexão e crítica, 26(4), 743-751. DOI:http://dx.doi.org/10.1590/S0102-79722013000400015.

Pavione, S. N. C. S., Avelino, B. C., \& De Souza Francisco, J. R. (2016). Fatores que influenciam o Processo de Ensino-Aprendizagem sob a Perspectiva de Estudantes do Curso de Ciências Contábeis: Análise em uma Instituição de Ensino Superior de Minas Gerais. Revista de Educação e Pesquisa em Contabilidade, 10(2), 196-219. DOI: http://dx.doi.org/10.17524/repec.v10i2.1371

Piaget, J. A. (1954). The Construction of Reality in the Child. Translated by Margaret Cook. Basic Books.

Piaget, J. A. (1970). Psicologia e pedagogia: a resposta do grande psicólogo aos problemas do ensino. São Paulo: Forense.

Piletti, N., \& Rossato, S. M. (2011). Psicologia da Aprendizagem: da teoria do condicionamento ao construtivismo. São Paulo: Contexto.

Prince, M. (2004). Does active learning work? A review of the research. Journal of engineering education, 93(3), 223-231. https://doi.org/10.1002/j.2168-9830.2004.tb00809.x

Rama, D. V. (1998). Learning by doing: Concepts and models for service-learning in accounting. Stylus Publishing, LLC.

Rios, R. P. (2011). Aplicação do método de casos no curso de Ciências Contábeis: um estudo empírico (Dissertação de Mestrado em Ciências Contábeis, Pontifícia Universidade Católica de São Paulo, São Paulo), 209.

Santos, L. A. F; Gaspari, S. S. L. C; Marques, M. S. Pesquisa Bibliométrica sobre os métodos de ensino em Contabilidade. Caderno de Administração, v. 24, n. 2, p. 60-71, 2016. Recuperado de http:// periodicos.uem.br/ojs/index.php/CadAdm/issue/view/1207

Souza Gil, E., Garcia, E. Y. A, Lino, F. M. A, \& Gil, J. L. V. (2012). Estratégias de ensino e motivação de estudantes no ensino superior. Vita et Sanitas, 6(1), 57-81. Recuperado de http://www.fug.edu.br/ revista/index.php/VitaetSanitas/article/view/51 